\title{
Stereotactic radiosurgery of residual or recurrent craniopharyngioma, after surgery, with or without radiation therapy
}

\author{
Shang-Ming Chiou, L. Dade Lunsford, ${ }^{1}$ Ajay Niranjan, Douglas Kondziolka, \\ and John C. Flickinger \\ Department of Neurological Surgery and Radiation Oncology, Center for Image-Guided Neurosurgery, \\ University of Pittsburgh Medical Center, Pittsburgh, PA 15213
}

This study evaluated the role of stereotactic radiosurgery in the multimodality management of craniopharyngioma patients whose prior therapies failed. Ten consecutive patients ( 3 males and 7 females) had radiosurgery for craniopharyngioma during a 10-year interval. Their ages ranged from 9 to 64 years (median, 14.5 years). The median interval between diagnosis and radiosurgery was 46.5 months. In total, 12 stereotactic radiosurgical procedures were performed to control the solid component of the tumor ( 2 intrasellar and 10 suprasellar tumors). The median tumor volume was $1.35 \mathrm{~cm}^{3}$. One to 9 isocenters with different beam diameters were used; the median marginal dose was $16.4 \mathrm{~Gy}$; and the dose to the optic apparatus was limited to less than $8 \mathrm{~Gy}$. Clinical and imaging follow-up data were obtained at a median of 63 months (range, 13-150 months) from radiosurgery. Overall, 7 of 12 tumors became smaller or vanished within a median of 8.5 months. Prior visual defects objectively improved in 6 patients. One patient with prior visual defect deteriorated further and lost vision 9 months after radiosurgery. Multimodality therapy is often necessary for patients with refractory solid and cystic craniopharyngiomas. Stereotactic radiosurgery is a reasonable option in select patients with small recurrent or residual craniopharyngioma. Neuro-Oncology 3, 159-166, 2001 (Posted to Neuro-Oncology [serial online], Doc. 00-049, May 7, 2001. URL <neuro-oncology.mc.duke.edu>)

Received 7 September 2000, accepted 16 January 2001.

${ }^{1}$ Address correspondence and reprint requests to L. Dade Lunsford, Professor and Chairman, Department of Neurological Surgery, Professor of Radiology and Radiation Oncology, The University of Pittsburgh, University of Pittsburgh Medical Center-Presbyterian, Suite B-400, 200 Lothrop St., Pittsburgh, PA 15213-2582. $\longrightarrow$ Traniopharyngioma is the most common intracranial nonglial tumor in children but is relatively rare in adults (Hoffman, 1994). Although considered histologically benign, these tumors are often associated with neurological deficits, cognitive disorders, and endocrinologic impairment. Some tumors exhibit finger-like attachments to critical structures such as the hypothalamus, optic nerves, pituitary stalk, and basal cerebrovasculature. CT and MRI studies demonstrate that approximately $60 \%$ of cases are primarily a solitary cyst, $30 \%$ manifest a small solid tumor with one or more cysts, and $10 \%$ are purely solid (Lunsford, 1989). Appropriate therapeutic options must be individualized for each patient.

Microsurgical excision remains the primary treatment for these patients. Multimodality management strategies include microsurgery (Duff et al., 2000; Sanford, 1994), stereotactic intracavitary irradiation (Pollock et al., 1995; Voges et al., 1997), and external beam fractionated radiation therapy (Rajan et al., 1993). A combination of treatment modalities is necessary for patients with refractory craniopharyngiomas containing both solid and cystic components. In view of the proximity of the tumor to the optic apparatus, stereotactic fractionated radiation therapy is often employed to treat residual tumor. In this article, we reviewed our experience with and results of 10 consecutive patients during a 10-year interval. The potential adjunctive role of radiosurgery is evaluated in the context of failure of other treatment options.

\section{Materials and Methods}

\section{Patient Series}

From January 1988 to July 1998, 11 consecutive patients with recurrent or residual craniopharyngiomas were treated by stereotactic gamma knife radiosurgery. Our early 
experience was published previously (Lunsford, 1989; Lunsford et al., 1994). One international patient was lost to follow-up. Ten patients ( 3 males and 7 females) were serially evaluated to a median of 63 months (range, 13-150 months) (Table 1). Patients' ages ranged from 9 to 64 years (median, 14.5 years). All patients had prior histologic confirmation either by stereotactic biopsy ( 2 patients) or craniotomy ( 8 patients). The median interval between histologic diagnosis and stereotactic radiosurgery was 46.5 months (range, 2 months to 12 years). Two patients ( 3 and 5) underwent radiosurgery twice because of tumor growth at a new location, which was not covered in the prior radiosurgery plan. Therefore, a total of 12 procedures ( 2 for intrasellar and 10 for suprasellar tumors) were performed on 10 patients.

Before radiosurgery, 4 patients $(2,4,5$, and 8$)$ had undergone at least 2 microsurgical resections by craniotomy. Three patients $(4,5$, and 6$)$ underwent transsphenoidal resections for intrasellar tumor components. Three patients $(1,2$, and 8$)$ had undergone stereotactic ${ }^{32} \mathrm{P}$-intracavitary irradiation. One patient (2) received both ${ }^{32} \mathrm{P}$ and fractionated external beam radiation. All patients had panhypopituitarism caused either by prior surgery or by the tumor, and all required regular hormone replacement. Only 2 patients ( 2 and 6 ) had normal visual acuity but mild visual field defects. Two patients had hydrocephalus. Eight of 12 tumors treated had a cystic component as demonstrated by imaging.

\section{Radiosurgical Technique}

All adult patients undergoing radiosurgery were given local anesthesia, whereas children less than 14 years of age received general anesthesia. After application of a Leksell model $G$ head frame, a high-resolution MRI was performed to define the target volume. Prior to 1991, stereotactic CT was used for target localization. The CT or MRI data were transferred to treatment-planning computers (Elekta Instruments Inc. Atlanta, Ga.).

The enhancing tumor margin served as the radiosurgical target. The target encompassed the entire tumor including cystic and solid components if the dose to the optic apparatus could be kept below 8 Gy. However, if the cys- tic component was large and approached the optic chiasm, radiosurgery was mainly prescribed for the solid tumor. The $50 \%$ isodose curve was used to enclose the tumor in 8 of 12 tumors (Fig. 1A and B). Three tumors were irradiated at $60 \%$ isodose, and another tumor was treated at the $70 \%$ isodose. The median tumor volume (12 tumors) was $1.35 \mathrm{cc}$ (range, $0.18-5.2 \mathrm{cc}$ ) with a mean of $1.74 \mathrm{cc}$. The Leksell Gamma Knife (Elekta Instruments Inc.) was used to deliver radiation in a single session using 1 to 9 isocenters (median, 2.5 isocenters) of different beam diameters (Table 2). A median dose of 16.4 Gy (range, 12.5-20 Gy) was prescribed for the tumor margin. When necessary, selected beam channels within each collimator were plugged to shift the peripheral isodose curves away from the optic nerve, chiasm, or tract. The maximal allowable dose to the optic apparatus was less than 8 Gy in patients who had not received prior radiation therapy (Flickinger et al., 1990a).

\section{Results}

Ten patients had follow-up clinical and MRI evaluations either at our institution or by their referring physicians. Initial follow-up MRIs were obtained at 3 months, then at 6 and 12 months. If the disease was stable, yearly clinical and neuroimaging follow-ups were then performed. Neuro-ophthalmologic as well as endocrinologic tests were requested at regular intervals. All clinical and neuroimaging data were reviewed at our center. The median postradiosurgery follow-up duration was 63 months (range, 13-150 months).

\section{Clinical Response}

There was no procedure-related mortality nor any perioperative complications. Within a median of 8 months (range, 2-94 months) after radiosurgery, objective improvement in visual acuity occurred in 6 of 10 patients, and 3 maintained their preoperative visual acuity (Table 2). Two patients ( 1 and 2 ) had delayed deterioration in vision after radiosurgery. One of these patients (2) had prior ${ }^{32} \mathrm{P}$ intracavitary and external beam irradiation and received a

Table 1. Clinical characteristics of 10 patients with recurrent or residual craniopharyngiomas

\begin{tabular}{|c|c|c|c|c|c|c|c|c|}
\hline $\begin{array}{l}\text { Patient } \\
\text { No. }\end{array}$ & Sex & Age & $\begin{array}{l}\text { Pre-GK } \\
\text { therapy }\end{array}$ & $\begin{array}{l}\text { Diagnostic } \\
\text { methods }\end{array}$ & $\begin{array}{c}\text { Diagnosis } \\
\text { to GK }\end{array}$ & Pre-GK vision & $\begin{array}{c}\text { Pre-GK } \\
\text { endocrinopathy }\end{array}$ & Hydrocephalus \\
\hline 1 & $\mathrm{~F}$ & 64 & $\mathrm{ORS}^{32} \mathrm{P}$ & Biopsy & $28 \mathrm{mo}$ & Defect & Panhypopituitarism & - \\
\hline 2 & $M$ & 18 & $C R 3 \times X R T^{32} \mathrm{P}$ & Craniotomy & $12 \mathrm{yr}$ & Normal & Panhypopituitarism & - \\
\hline 3 & $\mathrm{~F}$ & 11 & $\mathrm{CR}$ & Craniotomy & $11 \mathrm{mo}$ & Defect & Panhypopituitarism & + \\
\hline 4 & $\mathrm{~F}$ & 9 & $\mathrm{CR} 2 \times \mathrm{TS}$ & Craniotomy & $7 \mathrm{yr}$ & Defect & Panhypopituitarism & - \\
\hline 5 & $\mathrm{~F}$ & 9 & $\mathrm{CR} 2 \times \mathrm{TS}$ & Craniotomy & $33 \mathrm{mo}$ & Defect & Panhypopituitarism & - \\
\hline 6 & $\mathrm{~F}$ & 17 & CR TS & Craniotomy & $21 \mathrm{mo}$ & Normal & Panhypopituitarism & - \\
\hline 7 & $\mathrm{~F}$ & 12 & $\mathrm{CR}$ & Craniotomy & $5 \mathrm{yr}$ & Defect & Panhypopituitarism & - \\
\hline 8 & $M$ & 19 & CR $2 \times{ }^{32} \mathrm{P} 2 \times \mathrm{VPS}$ & Craniotomy & $5 \mathrm{yr}$ & Defect & Panhypopituitarism & + \\
\hline 9 & M & 9 & $\mathrm{CR}$ & Craniotomy & $61 \mathrm{mo}$ & Blind & Panhypopituitarism & - \\
\hline 10 & $\mathrm{~F}$ & 48 & CR & Biopsy & $2 \mathrm{mo}$ & Defect & Panhypopituitarism & - \\
\hline
\end{tabular}

Abbreviations: GK, gamma knife; ORS, Ommaya Reservoir System; ${ }^{32} \mathrm{P}$, phosphorus-32 intracavitary irradiation; CR, craniotomy; XRT, external radiation therapy; TS, transsphenoidal surgery; VPS, ventriculoperitoneal shunt. 

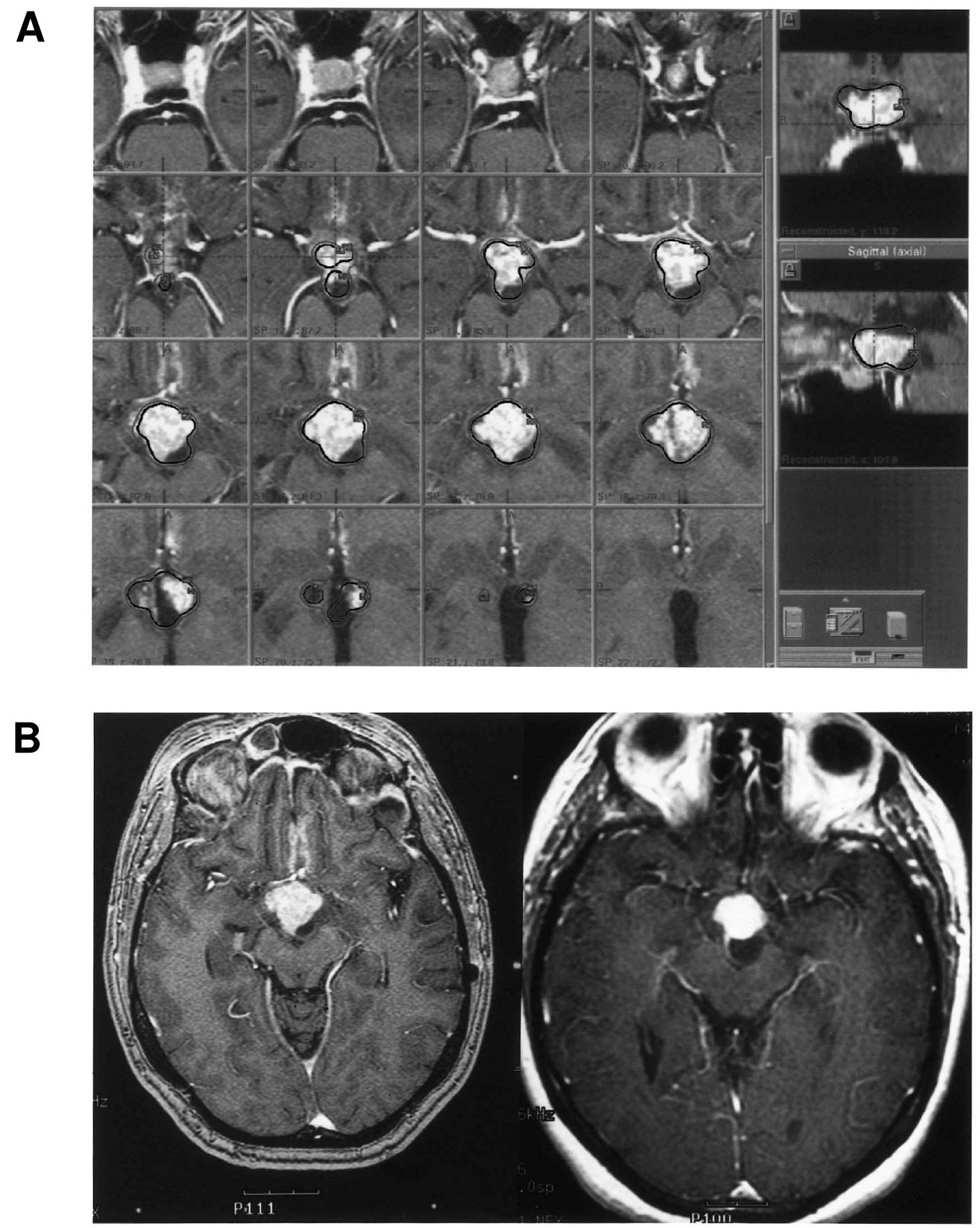

Fig. 1. A. Contrast-enhanced axial MRIs of a patient with sagittal and coronal reconstruction showing the radiosurgery dose plan with $50 \%$ (black line) and 40\% (gray line) isodose line covering solid and cystic tumors. Gamma knife radiosurgery was performed using a 13-Gy margin dose prescribed for the $50 \%$ isodose line. B. A contrast-enhanced axial MRI of the same patient before (left) and 13 months after (right) radiosurgery. The suprasellar craniopharyngioma appears stable.

16.7-Gy marginal radiosurgical dose. This patient had initial deterioration of vision followed by progressive improvement to the pretreatment baseline 5 months later. The other patient (1) also previously had ${ }^{32} \mathrm{P}$ intracavitary irradiation but received 20 Gy as a marginal radiosurgical dose. Her vision deteriorated 4 months after radiosurgery and progressed to complete blindness at 9 months postradiosurgery. This patient's 1-year followup MRI demonstrated tumor regression.

Serial neuroendocrinologic studies showed that all patients continued to exhibit anterior pituitary hormonal loss. No patient developed new-onset diabetes insipidus. 
Table 2. Clinical outcomes of 10 patients with 12 recurrent or residual craniopharyngiomas treated with radiosurgery

\begin{tabular}{|c|c|c|c|c|c|c|c|c|c|c|c|}
\hline $\begin{array}{l}\text { Patient } \\
\text { No. }\end{array}$ & $\begin{array}{l}\text { Tumor } \\
\text { location }\end{array}$ & Cyst & $\begin{array}{l}\text { Volume } \\
\text { (cc) }\end{array}$ & $\begin{array}{l}\text { Dmin } \\
\text { (Gy) }\end{array}$ & $\begin{array}{l}\text { Isodose } \\
(\%)\end{array}$ & $\begin{array}{c}\text { Length of } \\
\text { follow-up (mo) }\end{array}$ & $\begin{array}{l}\text { Vision } \\
\text { control }^{a}\end{array}$ & $\begin{array}{l}\text { Endocrine } \\
\text { abnormality }\end{array}$ & $\begin{array}{l}\text { Tumor } \\
\text { control }^{b}\end{array}$ & $\begin{array}{l}\text { Cyst } \\
\text { control }^{c}\end{array}$ & Remarks \\
\hline \multirow[t]{2}{*}{1} & Suprasellar & + & 3.06 & 20 & 70 & 68 & Loss (4) & Same & Smaller (11) & Drainage (5) & Reservoir reimplanted \\
\hline & & & & & & & & & & & $\begin{array}{c}5 \text { mo later; } \\
\text { craniotomy } 69 \text { mo later } \\
\text { for new cyst formation }\end{array}$ \\
\hline \multirow[t]{3}{*}{2} & Suprasellar & + & 3.09 & 16.7 & 50 & 121 & Improved (10) & Same & No growth & Smaller (5) & Vision initially worsened \\
\hline & & & & & & & & & & & $\begin{array}{l}5 \text { mo later; new } \\
\text { cyst formation } 51 \text { mo }\end{array}$ \\
\hline & & & & & & & & & & & later, but no operation \\
\hline \multirow[t]{2}{*}{3} & Suprasellar & - & 0.37 & 20 & 60 & 150 & Improved (3) & Same & Remission (12) & - & $\begin{array}{c}\text { Hydrocephalus improved } \\
\text { without operation }\end{array}$ \\
\hline & Intrasellar & - & 0.32 & 20 & 60 & 114 & Same & Same & No growth & - & Seizure 33 mo later \\
\hline \multirow[t]{2}{*}{4} & Intrasellar & + & 1.89 & 16 & 60 & 94 & Same & Same & No growth & Drainage (12) & Reservoir reimplanted \\
\hline & & & & & & & & & & & 12 mo later \\
\hline \multirow[t]{2}{*}{5} & Parasellar & + & 0.21 & 15 & 50 & 57 & Improved (2) & Same & Smaller (11) & Enlarged (31) & \\
\hline & Chiasm & - & 0.97 & 14 & 50 & 37 & Same & Same & Smaller (5) & - & \\
\hline 6 & $\begin{array}{l}\text { Supra/ } \\
\text { intrasellar }\end{array}$ & + & 1.73 & 18 & 50 & 70 & Improved (17) & Same & $\begin{array}{l}\text { Smaller (9) } \\
\text { Enlarged (70) }\end{array}$ & Enlarged (70) & $\begin{array}{l}\text { Tumor bleeding } 12 \text { mo } \\
\text { later, but no operation }\end{array}$ \\
\hline 7 & Suprasellar & + & 0.37 & 14 & 50 & 58 & Same & Same & Remission (58) & No growth & \\
\hline 8 & Suprasellar & + & 5.20 & 15 & 50 & 40 & Improved (10) & Same & Smaller (6) & Drainage (4) & ${ }^{32} \mathrm{P}$ and reservoir \\
\hline & & & & & & & & & Remission (40) & & implanted 4 mo later \\
\hline 9 & Suprasellar & - & 0.18 & 20 & 50 & 22 & Same & Same & Remission (22) & - & \\
\hline 10 & Suprasellar & + & 3.50 & 12.5 & 50 & 13 & Improved (8) & Improved & Smaller (3) & No growth & \\
\hline
\end{tabular}

Abbreviations: Dmin, minimum dose.

a,b,c Numbers in parentheses represent months after gamma knife when symptom or improvement was reported.

One patient (10) had improvement of her pre-existing diabetes insipidus 7 months later. A partial seizure occurred in 1 patient 33 months after her second radiosurgery (patient 3 ). Preoperatively, 2 patients (3 and 8 ) had ventricular enlargement, but their tumors completely resolved later. Neither patient required a shunt procedure. Although formal neuropsychologic testing was not performed, no patient or family member reported cognitive decline after radiosurgery.

\section{Tumor Response}

Two patients developed tumor recurrence at sites distant from previous radiosurgery. One patient (3), who initially had radiosurgery for her recurrent intra-third ventricle craniopharyngioma, was found to have a new recurrence in the sella at 1-year follow-up MRI. Her intraventricular lesion had disappeared completely. In view of her initial excellent response, her family opted for radiosurgery for the new recurrence in the sella. Sixmonth follow-up imaging showed reduction in the sellar tumor. Ten-year follow-up imaging of this patient continued to show no recurrence of the tumor in either location. Patient 5 was a 9-year-old girl who had recurrence despite two prior frontal craniotomies and one transsphenoidal removal. At radiosurgery, three separate areas of enhancements were noted: just below the left carotid artery, in the right cavernous sinus region, and in the left optic chiasm itself. Enhancement in the left optic chiasm was thought to be an enhancing scar and was not treated. Two lesions were treated by radiosurgery (15-Gy margin dose). The fifteen months' follow-up MRI showed regression in one and stable appearance of the other treated lesion. The untreated optic chiasm enhancement was larger in size, suggesting that this too represented a recurrent lesion. This lesion showed further growth and was treated by radiosurgery (14-Gy margin dose). The tumor showed regression in 5 months. A follow-up MRI at 37 months showed regressed and stable tumor size. Her vision was unchanged.

Three tumors (patients 2 and 4, and one tumor of patient 3) exhibited no further growth of tumor after radiosurgery. Five tumors (patients 1,8 , and 10, and both tumors of patient 5) showed regression at a median of 8 months postradiosurgery and continued to show regressed tumor at last follow-up (median 47 months) (for example, see Fig. 2 [patient 1]). Four tumors (patients 7,8 , and 9 , and 1 tumor of patient 3 ) resolved completely at $12,22,40$, and 58 months, respectively (for example, see Fig. 3 [patient 3]). One patient (6) had regression in tumor size by 9 months postradiosurgery but demonstrated some tumor enlargement at 70 months postradiosurgery.

Three patients (1, 4, and 8) required an Ommaya reservoir implantation for management of an expanding cyst noted at the time of radiosurgery. A new cyst developed in 2 patients ( 1 and 2 ) at 69 and 51 months, respectively, afterwards. One patient (1) thereafter underwent repeat craniotomy to relieve the increasing mass effect from the cyst (Table 3). 
A

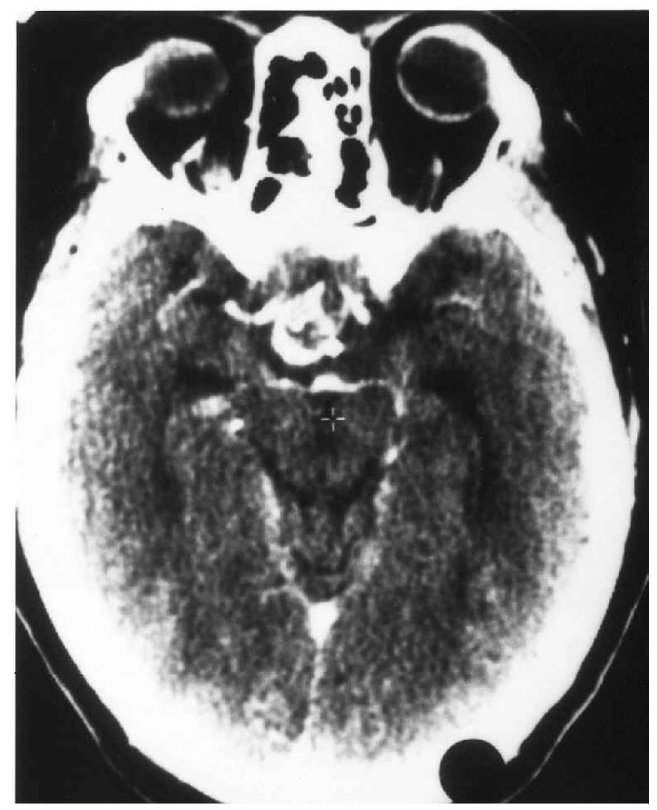

B

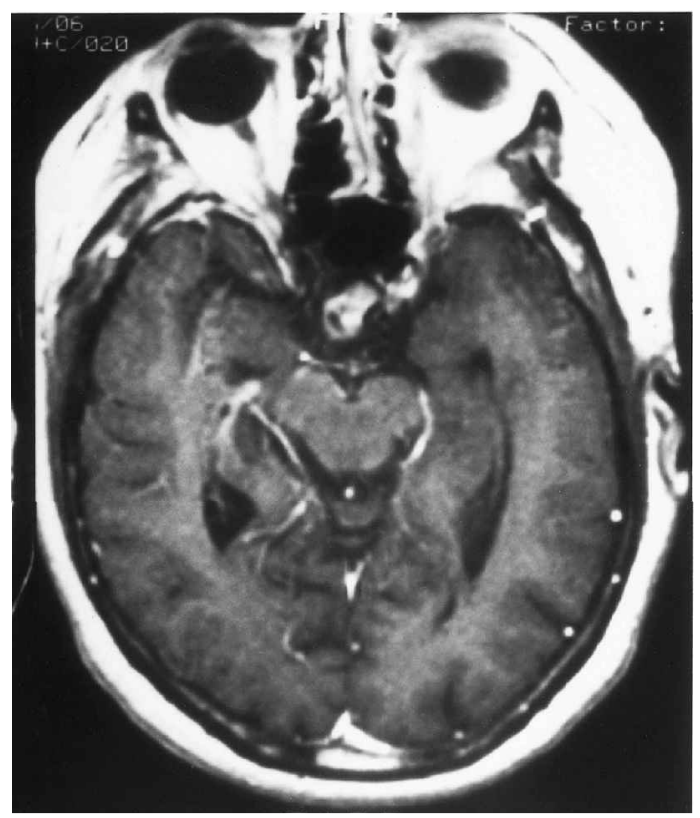

Fig. 2. (A) A contrast-enhanced CT scan showing a residual suprasellar craniopharyngioma and (B) a contrast-enhanced axial MRI for the same patient 30 months after radiosurgery revealing tumor regression.

\section{Discussion}

\section{Microsurgical Resection}

Surgical resection should be the first procedure considered for patients with an expanding cystic or solid craniopharyngiomas (Hoffman, 1994). With modern neurosurgical techniques, many tumors can be resected successfully. However, some tumors have no line of cleavage between the tumor and adjacent brain or vessels and therefore are difficult to excise completely (Duff et al., 2000; Hoffman, 1994). In their 30-year review, Prasad et al. (1995) reported that only $11(35.5 \%)$ of 31 reported surgical series had achieved more than $50 \%$ radical resection rate. Even after "total resection," long-term success has been questioned because of a $5 \%$ to $50 \%$ delayed recurrence rate (Duff et al., 2000; Prasad et al., 1995; Rajan et al., 1993; Wisoff, 1994).

An overview of published reports indicates an average of $12 \%$ (range, $2 \%-43 \%$ ) risk of operative mortality and $30 \%$ (range, $12 \%-61 \%$ ) incidence of severe morbidity. Morbidity includes the risk of disabling hypothalamic damage $(40 \%)$ and visual impairment $(19 \%)$ (Mark et al., 1995). Residual tumors generally progress within several years. Scarring from previous surgery may enhance the technical difficulty of repeat surgery and increase the surgical mortality and morbidity (Caldarelli et al., 1998; Wisoff, 1994). In such patients, more conservative alternative approaches are required, especially for patients with poor overall health.

\section{Conventional External Beam Radiation}

Fractionated external beam radiation therapy (150-180 cGy per fraction) is considered an optimal postoperative man- agement strategy for craniopharyngioma, as these tumors are radiosensitive (Flickinger et al., 1990). In 1993, Rajan et al. reviewed 31 reported series and concluded that limited surgery followed by fractionated external radiation provided excellent tumor control with a recurrence rate of $17 \%$ compared with $73 \%$ after subtotal resection only (Rajan et al., 1993). However, the potential risk of delayed hypothalamic-pituitary disturbance (Rajan et al., 1993; Sanford, 1994) is greater after conventional radiotherapy. Prevention of postradiotherapy late neuropsychological sequelae to the developing brain remains a serious concern. There is also a risk of tumor induction in a young child treated with radiotherapy (Hoffman, 1994; Prasad et al., 1995).

\section{Intracavitary Irradiation}

Cystic tumors ideally are treated by stereotactic puncture and intracavitary irradiation (Backlund et al., 1972; Pollock et al., 1995; Voges et al., 1997). In our previous experience (Pollock et al., 1995), cyst control (same or smaller volume) was obtained in $29(90.6 \%)$ of 32 treated cysts. The cyst decreased dramatically in 25 patients, disappeared in another 3, and remained the same size in 1 patient. Ten $(33 \%)$ patients required additional surgical intervention for tumor progression. Three $(10 \%)$ patients died: 2 of tumor progression and 1 of an unrelated cause. Preservation of vision or improvement of endocrine function was achieved in $69 \%$ of the intracavitary radiation-only group and in $31 \%$ of patients with recurrent tumors. However, cysts smaller than $3 \mathrm{ml}$ are difficult to treat by intracavitary irradiation. In addition, such treatment does not affect solid tumor growth (Lunsford, 1989). 

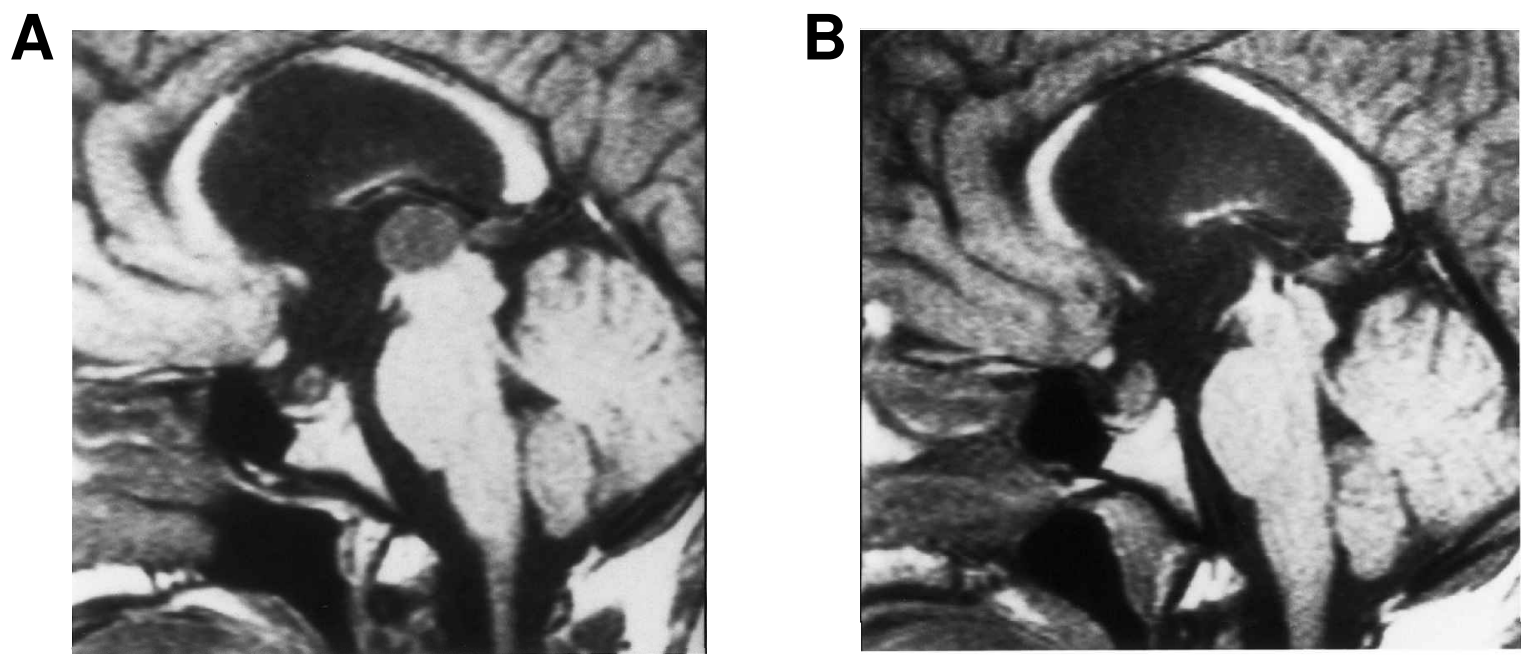

Fig. 3. Sagittal MRIs showing (A) a residual intraventricular cystic craniopharyngioma and (B), for the same patient 12 months after radiosurgery, complete tumor regression.

\section{Intracavitary Chemotherapy}

Intracystic administration of bleomycin to obliterate a craniopharyngioma cyst has been advocated as a therapeutic alternative (Broggi et al., 1996; Savas et al., 1999; Takahashi et al., 1985). Bleomycin is an antineoplastic antibiotic agent that interferes with DNA production. The goal of its use is to suppress the secretion of cystic fluid and cause tumor cells to degenerate. Broggi and Franzini (1996) reported promising long-term results after intracystic bleomycin administration. These authors reported complete disappearance of the cyst in 7 of 14 patients. Its potential risks are interstitial pulmonary fibrosis, alopecia (Prasad et al., 1995), and injury to the hypothalamus (Haisa et al., 1994).

\section{Stereotactic Radiosurgery}

Radiosurgery is a well-established technique that precisely delivers a large dose of irradiation to a small intracranial volume while minimizing the dose to the surrounding tissue. The technique is used for small craniopharyngiomas $(<2.5 \mathrm{~cm})$ that are, preferably, $2-3 \mathrm{~mm}$ or more distant from the optic apparatus (Laws and Vance, 1999; Lunsford et al., 1994). Radiosurgery may be used both as a prophylactic measure to prevent regrowth of a postoperative residual tumor and for treatment of a previously resected tumor that has recurred (Laws and Vance, 1999).

In 1965, Backlund et al. (1972) first advocated the use of gamma knife radiosurgery as adjunctive or potentially definitive treatment of solid craniopharyngiomas. At present, only scattered reports are available regarding results of gamma knife radiosurgery for these tumors (Table 4). The role of linear accelerator radiosurgery is still under investigation (Buatti et al., 1998). In the present study, 7 of 12 tumors regressed or disappeared within a median of 8.5 months after radiosurgery. Another 5 tumors remained unchanged over the follow-up interval. Vision was objectively improved in 6 of 10 patients.
Our results are comparable to previous reports (Kobayashi et al., 1994, 1999; Prasad et al., 1995).

A Boston group (Tarbell et al., 1996) used linear accelerator-based stereotactic radiation therapy to treat 21 patients with residual or recurrent craniopharyngioma between 1992 and 1995. Conventional fractionated doses $(1.8 \mathrm{~Gy} /$ fraction) delivered 5000 to $5400 \mathrm{cGy}$ in 28 to 30 fractions. With a median follow-up of 15 months, no patient had a recurrence or a treatmentrelated complication. Longer follow-up is needed to evaluate the effectiveness as well as late complication of this type of stereotactic radiation therapy. A conventional fractionation schedule would seem to avoid late cognitive effects after stereotactic radiation therapy. Because radiation delivery is guided using a relocatable head frame, a margin of surrounding normal tissue is included in the treatment volume, which can be excluded in single-session radiosurgery using rigid head fixation. Stereotactic radiation therapy, however, could be a logical choice for treating craniopharyngiomas that completely envelope the optic chiasm and are therefore not suitable for singlesession radiosurgery.

Table 3. Summary of pre- and postoperative adjunctive therapy in 10 patients with recurrent craniopharyngioma

\begin{tabular}{lcc} 
Procedure & $\begin{array}{c}\text { Before GK } \\
\text { radiosurgery }\end{array}$ & $\begin{array}{c}\text { After GK } \\
\text { radiosurgery }\end{array}$ \\
\hline Biopsy & 2 & 0 \\
Craniotomy & 8 & 1 (cyst) \\
${ }^{32}$ P intracavitary irradiation & 3 & 1 \\
External beam radiotherapy & 1 & 0 \\
CSF shunting & 1 & 0 \\
Cyst aspiration & 3 & 3 \\
Ommaya reservoir & 1 & 3 \\
\hline
\end{tabular}

Data are number of procedures performed in 10 patients.

Abbreviations: GK, gamma knife; CSF, cerebrospinal fluid. 
Table 4. Summary of results of gamma knife radiosurgery for craniopharyngiomas reported in various studies

\begin{tabular}{|c|c|c|c|c|c|c|c|c|c|}
\hline Studies & No. of Tumors & $\begin{array}{c}\text { Mean } \\
\text { follow-up (mo) }\end{array}$ & $\begin{array}{c}\text { Average } \\
\text { volume (cc) }\end{array}$ & $\begin{array}{c}\text { Mean } \\
\text { Dmin (Gy) }\end{array}$ & $\begin{array}{c}\text { Optic } \\
\text { dose (Gy) }\end{array}$ & Tumor control & Cyst control & Vision control & Endocrinopathy \\
\hline $\begin{array}{l}\text { Kobayashi et al., } \\
1994\end{array}$ & 10 & $13.9(4-28)$ & 6.14 & $14.2(12-18)$ & $<13$ & $\begin{array}{l}\text { Smaller } 7 \\
\text { Same } 3\end{array}$ & NA & $\begin{array}{c}\text { Improved } 2 \\
\text { Same } 7 \\
\text { Worse } 1\end{array}$ & $\begin{array}{l}\text { Same } 9 \\
\text { Worse } 1\end{array}$ \\
\hline $\begin{array}{l}\text { Prasad et al., } \\
1995\end{array}$ & 8 & $2-48$ & NA & $9-15$ & NA & $\begin{array}{c}\text { Smaller } 5 \\
\text { Same } 2 \\
\text { Enlarged } 1\end{array}$ & $\begin{array}{c}\text { Smaller } 2 \\
\text { Same } 1 \\
\text { Enlarged } 3\end{array}$ & NA & NA \\
\hline $\begin{array}{l}\text { Kobayashi et al., } \\
1999\end{array}$ & 33 & $42.1(24-78)$ & 8.37 & 12.8 & $<12$ & $\begin{array}{l}\text { Smaller } 27 \\
\text { Same } 1 \\
\text { Enlarged } 5\end{array}$ & Enlarged 5 & Worse 1 & $\begin{array}{l}\text { Same } 30 \\
\text { Worse } 3\end{array}$ \\
\hline $\begin{array}{l}\text { Present series, } \\
2000\end{array}$ & 12 & $67.8(13-150)$ & 1.04 & 17.2 & $<8$ & $\begin{array}{l}\text { Smaller } 9 \\
\text { Same } 3\end{array}$ & $\begin{array}{l}\text { Smaller } 1 \\
\text { Same } 2 \\
\text { Enlarged } 5\end{array}$ & $\begin{array}{c}\text { Improved } 6 \\
\text { Same } 3 \\
\text { Worse } 1\end{array}$ & $\begin{array}{l}\text { Improved } 1 \\
\text { Same } 9\end{array}$ \\
\hline
\end{tabular}

Abbreviations: Dmin, minimum dose; NA, data not available.

Therapeutic results of radiosurgery and its complications are closely related to the tumor margin dose, which is critically determined by tumor volume and proximity to critical structures (Kobayashi et al., 1999; Laws and Vance, 1999). In general, the best outcomes are achieved in small-volume tumors. Despite the rapid fall-off of irradiation outside the target volume, proximity of the optic nerves continues to pose the greater risk. Visual deterioration after radiosurgery was noted in 2 of our patients as well as in 1 patient reported by Kobayashi et al. (1994, 1999). This Japanese patient underwent external beam irradiation followed by radiosurgery (18 Gy marginal, $60 \%$ isodose). Preoperative imaging was unable to distinguish the optic nerve well (Kobayashi et al., 1994). In our series, both patients with visual deterioration had undergone ${ }^{32} \mathrm{P}$ intracavitary irradiation and 1 patient (2) also had fractionated irradiation before radiosurgery of 16.7-Gy marginal dose. In this case, visual deterioration was transient (Table 2). One patient lost vision despite documented solid tumor regression (marginal dose of $20 \mathrm{~Gy}, 50 \%$ isodose). However, a large cystic component continued to progress and required implantation of a cyst reservoir 5 months after radiosurgery. This limited experience reinforces the additional risks posed by a history of prior intracavitary or external beam radiation.

Although radiosurgery is indicated primarily for small-volume solid craniopharyngiomas (Kobayashi et al.,
1994; Laws and Vance, 1999; Lunsford et al., 1994), we consider radiosurgery in additional clinical presentations. About one-third of the craniopharyngiomas are mixed type, with one or more cysts. Cysts smaller than $3 \mathrm{ml}$ are difficult to treat by intracavitary irradiation (Lunsford, 1989), and in such patients, radiosurgery may be acceptable. In 1995, Prasad et al. reported a response rate of $50 \%$ in 6 mixed cystic tumors (2 cysts decreased and 1 cyst remained stable in size) after radiosurgery. In the present study of 8 mixed tumors, we achieved $37.5 \%$ response rate from treated cysts $(2$ cysts remained the preoperative size and another decreased in size) at a median of 62.5 months after treatment. Two new cysts developed in patients between 4 and 6 years after treatment. Additional experience is warranted to assess whether radiosurgery alone controls growth of small cystic craniopharyngiomas.

\section{Conclusion}

Although surgical resection remains the first consideration in the management of a solid craniopharyngioma, adjunctive treatment strategies are often needed to control tumor cysts and recurrence. Stereotactic radiosurgery has an important selective role in the multimodality management of craniopharyngioma.

\section{References}

Backlund, E.O., Johansson, L., and Sarby, B. (1972) Studies on craniopharyngiomas. II. Treatment by stereotaxis and radiosurgery. Acta Chir. Scand. 138, 749-759.

Broggi, G., and Franzini, A. (1996) Bleomycin for cystic craniopharyngioma. J. Neurosurg. 84, 1080-1081.

Buatti, J.M., Bova, F.J., Friedman, W.A., Meeks, S.L., Marcus, R.B., Jr., Mickle, J.P., Ellis, T.L., and Mendenhall, W.M. (1998) Preliminary experience with frameless stereotactic radiotherapy. Int. J. Radiat. Oncol. Biol. Phys. 42, 591-599.

Caldarelli, M., di Rocco, C., Papacci, F., and Colosimo, C., Jr. (1998) Management of recurrent craniopharyngioma. Acta Neurochir. 140, 447-454.

Duff, J.M., Meyer, F.B., Ilstrup, D.M., Laws, E.R., Jr., Schleck, C.D., and Scheithauer, B.W. (2000) Long-term outcomes for surgically resected craniopharyngiomas. Neurosurgery 46, 291-305.
Flickinger, J.C., Lunsford, L.D., Singer, J., Cano, E.R., and Deutsch, M. (1990a) Megavoltage external beam irradiation of craniopharyngiomas: Analysis of tumor control and morbidity. Int. J. Radiat. Oncol. Biol. Phys. 19, 117-122.

Flickinger, J.C., Maitz, A., Kalend, A., Lunsford, L.D., and Wu, A. (1990b) Treatment volume shaping with selective beam using the Leksell gamma unit. Int. J. Radiat. Oncol. Biol. Phys. 19, 783-789.

Haisa, T., Ueki, K., and Yoshida, S. (1994) Toxic effects of bleomycin on the hypothalamus following its administration into a cystic craniopharyngioma. Br. J. Neurosurg. 8, 747-750.

Hoffman, H.J. (1994) Surgical management of craniopharyngioma. Pediatr. Neurosurg. 21 (Suppl. 1), 44-49.

Kobayashi, T., Tanaka, T., and Kida, Y. (1994) Stereotactic gamma radiosurgery of craniopharyngiomas. Pediatr. Neurosurg. 21 (Suppl. 1), 69-74. 
Kobayashi, T., Kida, Y., and Mori, Y. (1999) Effects and prognostic factors in the treatment of craniopharyngioma by gamma knife. In: Alexander, III, E., Kondziolka, D., Lindquist, C., and Loeffler, J.S. (Eds.), Radiosurgery, Vol. 3. Basel: Karger. pp. 192-204.

Laws, E.R., Jr., and Vance, M.L. (1999) Radiosurgery for pituitary tumors and craniopharyngiomas. Neurosurg. Clin. N. Am. 10, 327-336.

Lunsford, L.D. (1989) Stereotactic treatment of craniopharyngioma: Intracavitary irradiation and radiosurgery. Cont. Neurosurg. 11, 1-6.

Lunsford, L.D., Pollock, B.E., Kondziolka, D.S., Levine, G., and Flickinger, J.C. (1994) Stereotactic options in the management of craniopharyngioma. Pediatr. Neurosurg. 21 (Suppl. 1), 90-97.

Mark, R.J., Lutge, W.R., Shimizu, K.T., Tran, L.M., Selch, M.T., and Parker, R.G. (1995) Craniopharyngioma: Treatment in the CT and MR imaging era. Radiology 197, 195-198.

Pollock, B.E., Lunsford, L.D., Kondziolka, D., Levine, G., and Flickinger, J.C. (1995) Phosphorus-32 intracavitary irradiation of cystic craniopharyngiomas: Current technique and long-term results. Int. J. Radiat. Oncol. Biol. Phys. 33, 437-446.

Prasad, D., Steiner, M., and Steiner, L. (1995) Gamma knife surgery for craniopharyngioma. Acta Neurochir. 134, 167-176.

Rajan, B., Ashley, S., Gorman, C.J., Jose, C.C., Horwich, A., Bloom, H.J.,
Marsh, H., and Brada, M. (1993) Craniopharyngioma: Long term results following limited surgery and radiotherapy. Radiother. Oncol. 26, 1-10.

Sanford, R.A. (1994) Craniopharyngioma: Results of survey of the American Society of Pediatric Neurosurgery. Pediatr. Neurosurg. 21 (Suppl. 1), 39-43.

Savas, A., Arasil, E., Batay, F., Selcuki, M., and Kanpolat, Y. (1999) Intracavitary chemotherapy of polycystic craniopharyngioma with bleomycin. Acta Neurochir. 141, 547-549.

Takahashi, H., Nakazawa, S., and Shimura, T. (1985) Evaluation of postoperative intratumoral injection of bleomycin for craniopharyngioma in children. J. Neurosurg. 62, 120-127.

Tarbell, N.J., Scott, R.M., Goumnerova, L.C., Pomeroy, S.L., Black, P.McL., Barnes, P., Billett, A., LaVally, B., Shrieve, D., Helmus, A., Kooy, H.M., and Loeffler, J.S. (1996) Craniopharyngioma: Preliminary results of stereotactic radiation therapy. In: Kondziolka, D., (Ed.), Radiosurgery, Vol. 1. Basel: Karger. pp. 75-82. [get copy of article from Duke Lib.]

Voges, J., Sturm, V., Lehrke, R., Treuer, H., Gauss, C., and Berthold, F. (1997) Cystic craniopharyngioma: Long-term results after intracavitary irradiation with stereotactically applied colloidal beta-emitting radioactive sources. Neurosurgery 40, 263-270.

Wisoff, J.H. (1994) Surgical management of recurrent craniopharyngiomas. Pediatr. Neurosurg. 21 (Suppl. 1), 108-113. 